\title{
Election for the Office of Dean
}

Votes were cast as follows:

Katona, Cornelius

Whyte, Susan F.

Bolton, Jeremy Shaw

Aveline, Mark
Deahl, Martin $\quad 367$

Harris, Mike 296

719

552 Professor Cornelius Katona has, therefore, 403 been elected Dean with effect from 1 July 3921998.

\section{Library and Information Service}

\section{Recent donations}

We wish to thank the following author-Members, and others, who have generously donated copies of their works to the College Library.

Alexander J. Botsis, Constantin R. Soldatos and Costas N. Stefanis (1997) Suicide. Biopsychosocial Approaches. Amsterdam: Elsevier (Donated Dr D. J. Pallis, contributor.)

Robert M. Cohen (1995) Patient Management Problems for the MRCPsych. Salisbury: Quay Books division of Mark Allen Publishing.

Peter Decalmer and Frank Glendenning (eds) (1997) The Mistreatment of Elderly People. London: Sage.

Michael Fitzgerald, Pat Matthews, Gail Birkberk and John O'Connor (1997) Irish Families Under Stress. Planning for the Future of Autistic Persons. A Prevalence and Psychosocial Study in the Eastern Health Board Area of Dublin. Volume 6. Dublin: Eastern Health Board.

Jeremy Holmes and Richard Lindley (1998) The Values of Psychotherapy (revised edn). London: Karnac Books.
Rachel Jenkins and T. Bedirhan Ustun (eds) (1998) Preventing Mental Illness. Mental Health Promotion in Primary Care. Proceedings of a Conference Organised by the Department of Health in Collaboration with the Royal Institute of Public Health and Hygiene and Co-Sponsored by the World Health Organization. Chichester: Wiley.

William Alwyn Lishman (1998) Organic Psychiatry: The Psychological Consequences of Cerebral Disorder. Oxford: Blackwell.

L. O'Brien (1998) Traumatic Events and Mental Health. Cambridge: Cambridge University Press.

Brian O'Shea (1997) Schizophrenia, The Cutting Edge. Dublin: Eastern Health Board.

Malcolm Pines (1998) Circular Reflections. Selected Papers on Group Analysis and Psychoanalysis. London: Jessica Kingsley

Basant K. Puri and Anne D. Hall (1998) Revision Notes in Psychiatry. London: Arnold.

This list is an acknowledgement of donors, not a current awareness or latest acquisitions list. If Members are interested in the publications listed, they are invited to contact the Library, which can supply full bibliographic details from the database, and a monthly current awareness list of latest acquisitions. 